\title{
A multivariate approach to analyzing the relation between occlusion and craniofacial morphology
}

\author{
S. D. Keeling, DDS, MS, ${ }^{\star}$ M. L. Rlolo, DDS, MS, ${ }^{\star \star}$ R. E. Martin, DDS, ${ }^{\star \star \star}$ \\ and T. R. Ten Have, MPH** \\ Gainesville, Fla., and Ann Arbor, Mich.
}

\begin{abstract}
This study examined the association between occlusion and craniofacial morphology using univariate and multivariate statistical methods. Data were obtained from study casts and lateral cephalometric radiographs of 164 children in the early permanent dentition. The following multiple features of occiusion were assessed: molar relation, overjet, overbite, and anterior crowding. Angular skeletal measures assessed cranial base flexure, maxillary horizontal and vertical positions, mandibular horizontal and vertical positions, horizontal and vertical maxillary-mandibular relations, and positions of the incisors. The relation between the Occlusal Index, which is a malocclusion severity index, and skeletal morphology was also investigated. Associations were examined by use of linear correlation, stepwise multiple regression, and canonical correlation analyses. Individually and in combination, occlusal features were poorly associated with individual skeletal measures $\left(r^{2} \leqslant 0.35\right)$. The strongest association occurred between a linear combination of occlusal features and a linear combination of skeletal measures $\left(\mathrm{R}^{2}=0.66, p=0.0001\right)$. A malocclusion severity index did not aid in the identification of craniofacial morphology. The results suggested that combinations of certain acclusal characteristics may be associated with specific skeletal types; however, a generalized statement of this concept could not be supported. (AM J Orthod Dentofac OrTHOP 1989;95:297-305.)
\end{abstract}

$\mathrm{O}_{\mathrm{r}}$ rthodontic diagnosis might be facilitated if the relationship between occlusion and craniofacial (C-F) morphology were better understood. Occlusions vary from optimal to severe malocclusion, with continuous variation between the two, and are an expression of bone growth, dental development, and neuromuscular maturation. ${ }^{1}$

The concept that definitive relationships exist between occlusion and craniofacial morphology is well known to orthodontists. ${ }^{1-3}$ Numerous studies have examined the relationship between a single characteristic of occlusion and craniofacial morphology. Morphologic differences have been demonstrated (1) between anterior open bite and deep bite cases, ${ }^{4-10}$ (2) hetween mandibular anterior crowded cases and cases with mandibular anterior spacing, ${ }^{11 \cdot 13}$ and (3) among the three Angle classes of malocclusion. ${ }^{1426}$

The results of these studies often are contradictory because of several problems inherent in examining the association between craniofacial morphology and occlusal relationships. Not only do most samples rarely include a typical assortment of occlusal variation, but

\footnotetext{
* Department of Orthodontics, University of Florida

**Center for Human Growth and Development, University of Michigan.

***Department of Denlal Education, University of Florida.
}

the Angle classification schemes alone do not best represent that variation (for review, see Moyers and Wainright, 1977). ${ }^{1}$ In addition it has been suggested that a malocclusion is the sum of several individual skeletal deviations of which none may be remarkable in and of itself. ${ }^{27,28}$ Thus the relationship between occlusion and craniofacial morphology might be better analyzed by examining multiple components of both occlusion and skeletal morphology. Frequently applied univariate statistical techniques cannot cope with such a complex problem.

Solow ${ }^{29}$ examined the association between skeletal and occlusal measures using linear correlation and factor analysis procedures. This latter multivariate technique identified several orthogonally derived factors composed of both occlusal and skeletal measures but did not directly examine the relationship between multiple occlusal variables and multiple skeletal morphologic measures.

Multiple features of occlusion have been combined by epidemiologists in attempts to objectively determine malocclusion severity. For example, the Treatment Priority Index (TPI) and the Occlusal Index (OI) score malocclusion severity by ranking multiple components of a malocclusion. ${ }^{30.31}$ A severity index, based on occlusal features alone, would be more valuable if it were 

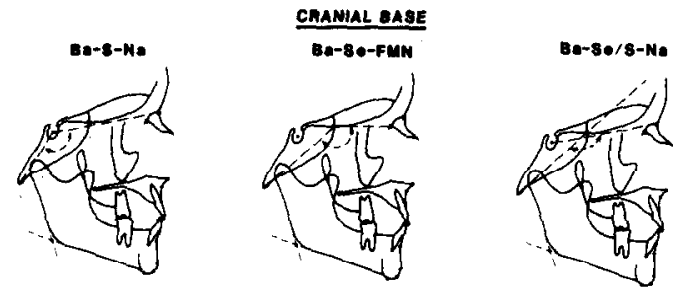

MAXIHLAAY HORIZONTAL POSITION
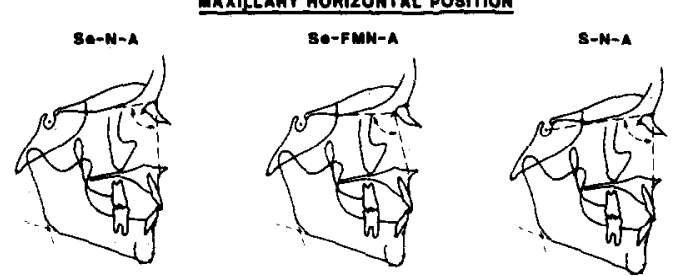

MAMOIBULAA HORIZONTAL POSITIOH
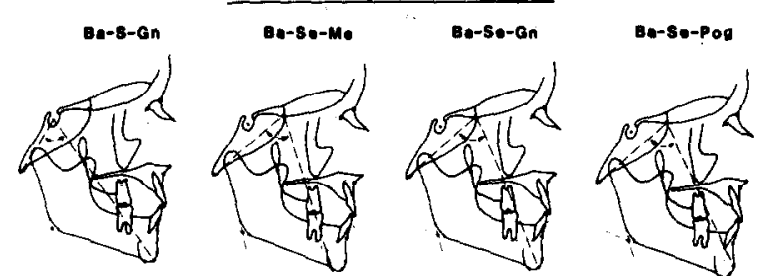

Fig. 1. Angular cephalometric measures, grouped by skeletal feature (CFF).

associated with craniofacial morphology, since there is some evidence that orthodontic patients seek care because of facial dysmorphology. ${ }^{32}$ The relationship between a malocclusion severity index and C-F morphology has not been investigated previously.

This study examined multiple features of both occlusion and craniofacial morphology to determine whether the association between occlusion and $\mathrm{C}-\mathrm{F}$ morphology was better explained by combinations of these features. In addition the relationship between a malocclusion severity index (a composite of occlusal features) and skeletal morphology was examined.

\section{METHODS AND MATERIALS The sample}

The data were obtained from pretreatment cephalometric radiographs and dental casts of all white children with intact pretreatment records who had a Class I or II molar relationship in the early permanent dentition and who had begun treatment during a 2-year period at a university orthodontic clinic. There were 64 boys (ages ranged from 9.3 to 16.2 years) and 100 girls (ages ranged from 9.2 to 15.7 years). Intact records consisted of clinically acceptable, conventionally trimmed dental casts and lateral cephalometric radiographs taken with the teeth in occlusion. All pri- mary teeth were absent; however, the second premolar and/or second molars were in various stages of emergence and/or eruption.

\section{Skeletal morphologic assessment}

The lateral cephalograms were traced by one investigator (S.D.K.). Landmarks were identified as described by Riolo and associates. ${ }^{33}$ All tracings were digitized on a Hipad digitizer, interfaced with an IBM-PC AT computer.

The angular measures selected to assess craniofacial morphology described nine craniofacial features (CFF): cranial base flexure, maxillary horizontal position, mandibular horizontal position, mandibular vertical position, maxillary vertical position, anteroposterior maxillary-mandibular discrepancy, mandibular incisor position, maxillary incisor position, and vertical maxillary-mandibular discrepancy (Fig. 1). Many common cephalometric measures (ANB, FMA) used to segregate cases (maxillary-mandibular discrepancy, steep angle) show serious variability through time in an individual and are therefore an improper representation of pattern. ${ }^{34}$ The angular measurements selected for this study may better represent the concept of morphologic pattern ${ }^{35}$; where possible, two or three measures were chosen to represent a specific skeletal feature (CFF).

\section{Occlusal assessment}

Six occlusal measures were examined: molar relation, overjet, overbite, maxillary anterior crowding, mandibular anterior crowding, and Occlusal Index score.

Molar relation was scored by the following ordinal method for both right and left sides: (1) bilaterally greater than cusp-to-cusp Class II; (2) one side cuspto-cusp Class II, one side greater than cusp-to-cusp Class II; (3) bilaterally cusp-to-cusp Class II; (4) one side cusp-to-cusp Class II, one side Class I; and (5) bilaterally Class $I$.

Overjet was measured at the level of the occlusal plane to the nearest millimeter with a ruler. Depth of incisor overbite, depicted by the amount of lower incisor coverage at the level of the occlusal plane, was scored by the following ordinal method: $(0) \leqslant 0$, (1) $>0$ to $\leqslant 1 / 3,(2)>1 / 3$ to $\leqslant 2 / 3$, (3) $>2 / 3$ to $<3 / 3$, (4) $=3 / 3$, and $(5)>3 / 3$.

The amount of anterior crowding in the maxilla and mandible was determined by Summer's tooth displacement rules..$^{3 i}$ Crowding equaled the number of teeth rotated $\geqslant 35^{\circ}$ and $\leqslant 45^{\circ}$ or displaced $\geqslant 1.5 \mathrm{~mm}$ and $\leqslant 2$ $\mathrm{mm}$ plus two times the number of teeth rotated $>45^{\circ}$ 


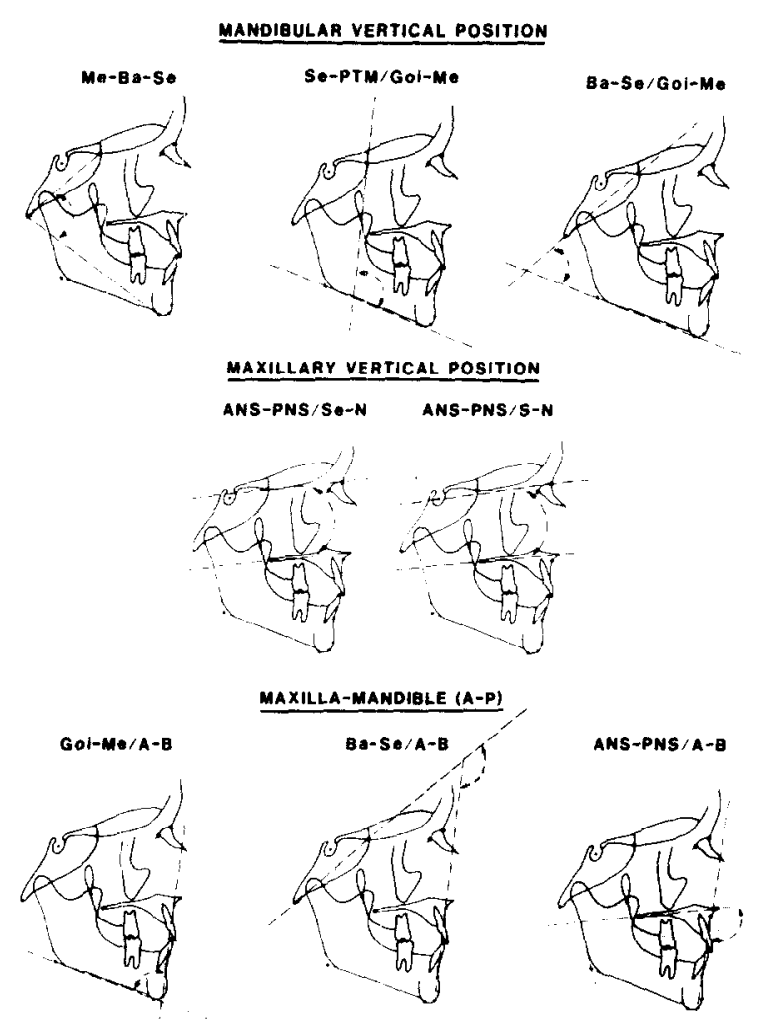

Fig. 1 (Cont'd).

or displaced $>2 \mathrm{~mm}$. Premolars and molars were not scored.

An Occlusal Index score was determined for each set of casts as described by Summers. ${ }^{31}$ The requirements for an index of occlusion have been summarized in a World Health Organization report. ${ }^{36}$ When these criteria for selection of an index of occlusion were tested, Summers demonstrated that the Occlusal Index was a more valid method of assessing severity of a malocclusion than the Malocclusion Severity Index or the Treatment Priority Index. Further, Grewe and Hage $^{37}$ compared the precision or change error and the bias or systematic error of three malocclusions indices: (1) the Handicapping Malocclusion Assessment Record (HMAR), (2) the Occlusal Index (OI), and (3) the Treatment Priority Index (TPI). These indices did not differ significantly with regard to precision or intra- and interexaminer reliability. The OI was found to be the index of choice with regard to having the least amount of systematic error.

\section{Reliability}

We evaluated tracing and digitizing intrajudge reliability for each skeletal variable. The mean total error

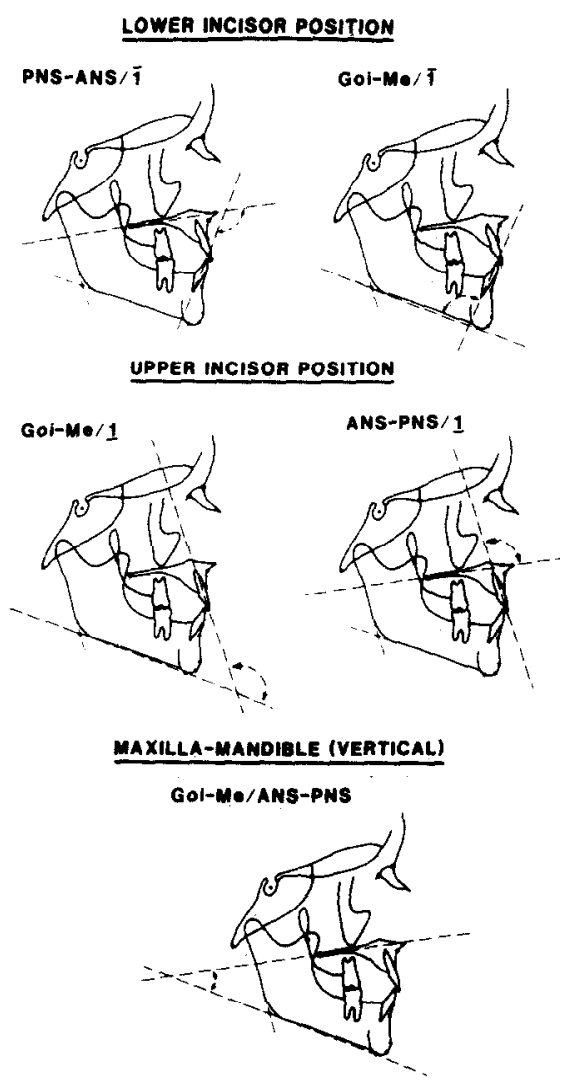

Fig. 1 (Cont'd).

was $0.74^{\circ}\left(\mathrm{SD}=0.23^{\circ}\right)$; the mean digitizing error was $0.21^{\circ}\left(\mathrm{SD}=0.08^{\circ}\right)$. The greatest tracing errors involved the determination of the position of frontomaxillary nasal (FMN) point and the positions of the incisors.

\section{Statistical analysis}

The first step was to inspect the correlations among occlusal characteristics, among skeletal measures by category (CFF), and between individual occlusal characteristics and skeletal mcasurcs. Pearson productmoment correlation coefficients were calculated between continuous variables; Spearman correlation coefficients were calculated when ordinal variables (molar relation, overbite) were involved.

In the second step, the stepwise regression procedure was used to determine whether combinations of occlusal characteristics explained more variance in any single skeletal measure than did single characteristics. ${ }^{38}$ In this procedure an occlusal variable was entered and retained in the regression model at each step if it explained a significant amount of skeletal measure vari- 
Table IA. Characteristics of the sample population-Age and continuous occlusal characteristics (64 boys, 100 girls)

\begin{tabular}{|c|c|c|c|c|c|c|c|}
\hline & Mean & $S D$ & Skewness & Kurtosis & Difference & $t$ & $p$ \\
\hline \multicolumn{8}{|l|}{ Age } \\
\hline Boys & 12.70 & 1.30 & 0.30 & 0.30 & & & \\
\hline Girls & 12.59 & 1.31 & 0.08 & -0.07 & 0.11 & -0.51 & NS \\
\hline \multicolumn{8}{|l|}{ Overjet } \\
\hline Boys & 5.81 & 3.09 & 0.92 & 0.81 & & & \\
\hline Girls & 5.14 & 2.24 & 0.33 & -0.48 & 0.67 & -1.51 & NS \\
\hline \multicolumn{8}{|c|}{ Maxillary crowding } \\
\hline Boys & 2.36 & 2.40 & 1.22 & 1.79 & & & \\
\hline Girls & 2.70 & 2.37 & 0.97 & 0.76 & 0.34 & 0.89 & NS \\
\hline \multicolumn{8}{|c|}{ Mandibular crowding } \\
\hline Boys & 2.61 & 2.19 & 0.33 & -0.92 & & & \\
\hline Girls & 2.40 & 1.97 & 0.77 & 1.03 & 0.21 & -0.63 & NS \\
\hline \multicolumn{8}{|c|}{ Occlusal index score } \\
\hline Boys & 9.78 & 3.77 & 0.14 & -0.46 & & & \\
\hline Girls & 9.55 & 2.96 & 0.09 & 0.26 & 0.23 & -0.43 & NS \\
\hline
\end{tabular}

Table IB. Characteristics of the sample population-Distribution of molar scores

\begin{tabular}{l|c|c|c|c|c}
\hline & \multicolumn{6}{|c}{ Molar score* $^{*}$} & 1 & 2 & 3 & 4 & 5 \\
\cline { 2 - 6 } & 16 & 5 & 7 & 4 & 32 \\
Boys & 16 & 8 & 5 & 11 & 51 \\
\hline
\end{tabular}

$* d f=4 ; \chi^{2}=2.85 ; p=\mathrm{NS}$

ance at the $p=0.05$ significance level. Addition of occlusal variables to the model was stopped when no other variable met the 0.05 significance level criterion.

Finally a canonical correlation analysis was performed to determine whether there were any linear combinations of occlusal features that were significantly correlated with linear combinations of skeletal measures. ${ }^{38,39}$ All analyses were performed by use of the SAS statistical package. ${ }^{40}$

\section{RESULTS}

\section{Sample population description}

The distribution of continuous variables for the entire sample was assessed by examining plots of the data and by calculating skewness and kurtosis values for these variables. The results indicated that all of the continuous variables were normally distributed (approximately) except for the indices for maxillary crowding and mandibular crowding. Skewness values ranged from -0.26 to 1.04 ; kurtosis values ranged from
Table IC. Characteristics of the sample population - Distribution of overbite scores

\begin{tabular}{l|c|c|c|c|c|c}
\hline & \multicolumn{6}{|c|}{ Overbite score* $^{*}$} \\
\cline { 2 - 7 } & 0 & 1 & 2 & 3 & 4 & 5 \\
\hline Boys & 2 & 16 & 17 & 25 & 3 & 1 \\
Girls & 4 & 23 & 49 & 20 & 3 & 1 \\
\hline
\end{tabular}

$* d f=5 ; \chi^{2}=10.74 ; p=\mathrm{NS}$.

-0.24 to 1.04 . (The statistical program defined normal curve skew and kurtosis as equal to 0 .)

Age and continuous measures of occlusal features by sex are reported in Table IA. As shown, the boys and girls did not differ significantly in age or the continuous occlusal measures.

The distributions of molar and overbite scores are reported in Table IB and IC. Chi square tests showed no significant differences between boys and girls in these ordinal measures.

The angular cephalometric measures for each sex wcrc normally distributed* except for the two measures describing maxillary vertical position in boys. Three variables displayed sexual dimorphism in our sample: (1) Ba-S-Na, (2) Ba-S-Gn, and (3) ANS-PNS / A-B

Because the male and female subjects did not generally differ in occlusal features and skeletal measures, the data were combined.

*Original research data available on request. 
Table II. Correlations between occlusal characteristics

\begin{tabular}{l|c|c|c|c}
\hline \multicolumn{1}{c|}{ Characteristic } & Overjet & Overbite & $\begin{array}{c}\text { Maxillary } \\
\text { crowding }\end{array}$ & $\begin{array}{c}\text { Mandibular } \\
\text { crowding }\end{array}$ \\
\hline Molar & $-0.48^{*}$ & $-0.28^{*}$ & -0.06 & $0.26^{*}$ \\
Overjet & & $0.34^{*}$ & $-0.30^{*}$ & $-0.51^{*}$ \\
Overbite & & 0.13 & $0.39^{*}$ & 0.04 \\
Maxillary crowding & & & $0.33^{*}$ & $0.34^{*}$ \\
Mandibular crowding & & & $0.46^{*}$ \\
\hline
\end{tabular}

* Correlations significantly different from zero at $p<0.001$.

\section{Correlations between occlusal characteristics}

The correlations between occlusal features (molar, overjet, overbite, crowding, and Occlusal Index) are reported in Table II. They ranged from 0.04 to 0.51 in absolute value. Molar and Occlusal Index had the largest correlation. The Occlusal Index was significantly associated with each of the occlusal features that comprised it. Although several of the relationships had moderately large correlations, none appeared redundant since a correlation of 0.51 denoted a shared variance of only $26 \%$. Thus, with minimal suggested redundancy, all occlusal variables were retained and later evaluated in relation to skeletal morphology.

These correlations showing high molar scores (i.e., Class I) were significantly associated with decreased overjet, decreased overbite, increased mandibular crowding, and low Occlusal Index scores.

\section{Correlations among skeletal measures}

The angular cephalometric measures within eight of the nine $\mathrm{CFF}$ categories were highly correlated ( $r$ ranged from 0.66 to $0.99, p<0.001$ ).* This was expected because measures within each CFF shared common landmarks. ${ }^{41}$ The exception involved measures assessing the A-P relation of the maxilla and mandible.

\section{Correlations between individual occlusal characteristics and individual skeletal measures}

The correlations between individual occlusal features and individual skeletal measures ranged from 0.00 (Ba-S-Na and ovejet, ANS-PNS/Goi-Me and overjet) to -0.56 (Goi-Me/A-B and molar) (Table III). Molar relation had the highest overall correlation to an individual skeletal measure, explaining (at $r=0.56$ ) $31 \%$ of the variance in the maxilla-to-mandible (A-P) measure. Occlusal features were poorly correlated with measures that described maxillary horizontal position,

*Original research datat available on request. mandibular horizontal position, and maxillary vertical position. Occlusal features were more highly associated with measures describing the maxilla-to-mandible anteroposterior relationship and upper incisor position.

\section{Stepwise multiple regression: Six occlusal characteristics and single skeletal measures}

One skeletal variable from each of the nine CFF categories was selected on the basis of strength of overall relation with occlusal variables, least amount of tracing error, absence of sexual dimorphism in the sample, and higher correlation with other measures in their own category (CFF). Stepwise regressions were carried out for these nine dependent skeletal variables. ${ }^{*}$ Total explained variance ranged from zero to $35 \%$.

Molar relation entered the prediction formula for all skeletal measures except those depicting the horizontal and vertical positions of the maxilla and the horizontal position of the mandible. Molar relation alone was the best predictor of the selected measures assessing cranial base flexure and mandibular vertical position, explaining $5 \%$ and $10 \%$ of the variance in those measures. No set of occlusal features was found to predict either maxillary horizontal position, mandibular horizontal position, or maxillary vertical position.

In four of nine regressions, two or more occlusal characteristics entered the prediction formula. However, multiple occlusal features added very little explained variance to the skeletal measure. For example, molar relation explained $4 \%$ of the variance in the maxilla to mandible (vertical) measure; adding Occlusal Index score explained an additional $2 \%$. A notable exception was the prediction of upper incisor position (Up Inc/ANS-PNS). Although overjet alone explained $17 \%$ of the variance, adding Occlusal Index, overbite, and molar relation doubled the amount of explained vari ance $(35 \%, p<0.05)$.

*Original research data available on request. 
Table III. Correlations between occlusal characteristics and individual skeletal measures

\begin{tabular}{|c|c|c|c|c|c|c|}
\hline Characteristic & Molar & Overjet & Overbite & $\begin{array}{l}\text { Maxillary } \\
\text { crowding }\end{array}$ & $\begin{array}{l}\text { Mandibular } \\
\text { crowding }\end{array}$ & $\begin{array}{c}\text { Occlusal } \\
\text { Index } \\
\text { score }\end{array}$ \\
\hline \multicolumn{7}{|l|}{ Cranial base } \\
\hline $\mathrm{Ba}-\mathrm{S}-\mathrm{Na}$ & $-0.18^{*}$ & 0.00 & 0.06 & 0.01 & 0.01 & 0.02 \\
\hline Ba-SE-FMN & $-0.22 * *$ & 0.20 & 0.07 & -0.02 & 0.00 & $0.15^{*}$ \\
\hline $\mathrm{Ba}-\mathrm{SE} / \mathrm{S}-\mathrm{Na}$ & $-0.21 * *$ & 0.14 & 0.06 & -0.04 & 0.01 & 0.11 \\
\hline \multicolumn{7}{|c|}{ Maxillary horizontal position } \\
\hline SE-N-A & 0.00 & -0.06 & 0.06 & -0.07 & -0.13 & -0.13 \\
\hline SE-FMN-A & 0.06 & -0.06 & 0.03 & -0.14 & -0.11 & $-0.16^{*}$ \\
\hline S-N-A & -0.04 & 0.08 & 0.10 & -0.13 & $-0.16^{*}$ & -0.09 \\
\hline \multicolumn{7}{|c|}{ Mandibular horizontal position } \\
\hline $\mathrm{Ba}-\mathrm{S}-\mathrm{Gn}$ & $-0.17^{*}$ & -0.01 & 0.14 & -0.08 & -0.11 & -0.05 \\
\hline Ba-SE-Gn & -0.14 & 0.05 & 0.13 & -0.11 & -0.13 & -0.03 \\
\hline Ba-SE-Pog & -0.13 & 0.05 & 0.13 & -0.12 & -0.13 & -0.05 \\
\hline \multicolumn{7}{|l|}{ Maxillary vertical position } \\
\hline ANS-PNS/SE-Na & -0.01 & 0.08 & 0.03 & -0.04 & 0.02 & 0.01 \\
\hline ANS-PNS/S-Na & 0.04 & -0.07 & -0.01 & -0.02 & 0.02 & -0.08 \\
\hline \multicolumn{7}{|c|}{ Mandibular vertical position } \\
\hline $\mathrm{Me}-\mathrm{Ba}-\mathrm{SE}$ & $0.24 * *$ & -0.10 & -0.15 & 0.10 & 0.11 & -0.03 \\
\hline SE-PTM/Goi-Me & $0.32 * * *$ & -0.09 & -0.16 & 0.01 & 0.10 & -0.15 \\
\hline Ba-SE/Goi-Me & $0.32^{* * *}$ & -0.12 & $-0.22 * *$ & 0.08 & 0.15 & -0.09 \\
\hline \multicolumn{7}{|l|}{ Maxilla to mandible (A-P) } \\
\hline Goi-Me/A-B & $-0.56^{* * *}$ & $0.28 * * *$ & $0.32 * * *$ & -0.05 & -0.05 & $0.19^{*}$ \\
\hline $\mathrm{Ba}-\mathrm{SE} / \mathrm{A}-\mathrm{B}$ & $-0.19^{*}$ & $0.18^{*}$ & 0.07 & -0.01 & -0.03 & 0.09 \\
\hline ANS-PNS/A-B & $-0.48 * * *$ & $0.31 * * *$ & 0.13 & -0.02 & -0.03 & $0.20^{* *}$ \\
\hline \multicolumn{7}{|c|}{ Maxilla-mandible (vertical) } \\
\hline ANS-PNS/Goi-Me & $0.20^{*}$ & 0.00 & $-0.23 * *$ & 0.07 & $0.18^{*}$ & 0.02 \\
\hline \multicolumn{7}{|l|}{ Upper incisor } \\
\hline Up Inc/Goi-Me & 0.13 & $0.32 * * *$ & $-0.28 * * *$ & $-0.22^{* *}$ & 0.01 & -0.11 \\
\hline Up Inc/ANS-PNS & 0.02 & $0.41^{* * *}$ & $-0.18^{*}$ & $-0.34 * * *$ & -0.12 & $-0.16^{*}$ \\
\hline \multicolumn{7}{|l|}{ Lower incisor } \\
\hline Lo Inc/ANS-PNS & -0.09 & $0.16^{*}$ & $-0.21 * *$ & 0.02 & 0.02 & 0.05 \\
\hline Lo Inc/Goi-Me & $-0.27 * * *$ & $0.19^{*}$ & -0.06 & -0.05 & -0.14 & 0.03 \\
\hline
\end{tabular}

Level at which correlations were significantly different from zero: $*_{p}<0.05 ; * * p<0.01 ; * * * p<0.001$.

\section{Canonical correlations: Combinations of occlusal characteristics and combinations of skeletal measures}

Because the previous steps showed low to moderate correlations and explained variances, canonical correlation analyses were performed to determine whether any linear combinations of occlusal characteristics were highly correlated with any linear combinations of skeletal measures.

The association of all six occlusal measures with all 22 skeletal variables was investigated initially. This association ( $\mathrm{R}=0.86, p=0.0001)$ proved to be the strongest discovered, but could not be interpreted because of the number of variables involved. The number of variables in the occlusal canonical variable (OCV) and in the skeletal canonical variable (SCV) was systematically reduced to discover a more parsimonious set for interpretation.
Dropping Occlusal Index score and mandibular crowding score from OCV and all but five skeletal measures from SCV did not significantly weaken the canonical correlation. Thus the most parsimonious set of variables in the canonical correlation analysis included four occlusal measures and five skeletal measures describing four CFF categories. The results are reported in Table IV, with a correlation of 0.81 and explained variance of $66 \%(p=0.0001)$.

Both standardized and raw coefficients for canonical variables are reported. These raw coefficients can be compared with those from other studies. In Table IV, the standardized coefficients indicated that overjet contributed more than three times as much weight to OCV as did molar relation and overbite. Looking at the standardized SCV, the five skeletal measures contributed about equally. Thus, accounting for the sign of the coefficients in OCV and SCV, two distinct relationships were demonstrated. Large overjet, low molar score 
Table IV. Canonical correlation analysis with component occlusal and skeletal measures*

\begin{tabular}{l|c|c|c|c}
\hline \multicolumn{2}{c|}{ Occlusal canonical variable $(\mathrm{OCV})$} & \multicolumn{2}{c}{ Skeletal canonical variable (SCV) } \\
\hline $\begin{array}{c}\text { Occluscl } \\
\text { characteristic }\end{array}$ & $\begin{array}{c}\text { Raw canonical } \\
\text { coefficient }\end{array}$ & $\begin{array}{c}\text { Standardized } \\
\text { canonical } \\
\text { coefficient }\end{array}$ & Skeletal measure & $\begin{array}{c}\text { Standardized } \\
\text { canonical } \\
\text { coefficient }\end{array}$ \\
\hline Molar & -0.15 & -0.26 & Ba-SE/Goi-Me & -0.11 \\
Overjet & 0.33 & 0.86 & Goi-Me/A-B & 0.10 \\
Overbite & -0.23 & -0.25 & Ba-SF/A-B & 0.08 \\
Maxillary crowding & -0.05 & -0.12 & UpInc/ANS-PNS & 0.99 \\
& & & ANS-PNS/Goi-Me & 0.90 \\
\hline
\end{tabular}

* Canonical correlation $=0.81 ;$ squared canonical correlation $=0.66 ;$ approximate $\mathrm{F}=14.04 ; d f=20,515 ; p=0.0001$.

(Class II), shallow overbite, and a tendency for minimal maxillary crowding were associated with a flat mandibular plane, large maxillary-mandibular (A-P) discrepancy, divergent palatal plane-mandibular plane angle, and upper incisor proclination.

Reversing signs of all coefficients suggested that minimal overjet, Class I, deep overbite, and a tendency for maxillary crowding were associated with a steep mandibular plane, small maxillary-mandibular (A-P) discrepancy, an acute palatal plane-mandibular plane angle, and retroclined upper incisors.

\section{DISCUSSION}

This study investigated the relationship between features of occlusion and craniofacial morphology. The concept of occlusion was not hased on a single component but rather on several aspects of occlusion: molar relation, overjet, overbite, and crowding. The relation between a malocclusion severity index, based on multiple aspects of occlusion, and craniofacial morphology was also investigated. Sexual dimorphism in occlusal and skeletal measures was not generally evident in our sample. However, a truer test of such sex differences should be made on a sample more representative of the population than our orthodontic sample.

The relationships were evaluated by use of linear correlation, stepwise regression, and canonical correlation analyses. Individual features of occlusion were poorly related tc individual skeletal measures; the highest correlation $(r=-0.56)$ explained only $31 \%$ of the variance between molar relation and Goi-Me/A-B. The low correlation of these singular relationships agreed with the findings of Solow ${ }^{29}$ and may explain why previous investigators have not reached agreement in evaluating single components of malocclusion. It was interesting that molar relation, overjet, and overbite generally had higher correlations with individual skeletal measures than did the Occlusal Index score, which was derived from those components.
On the basis of clinical impressions, we expected combinations of occlusal features to explain a much greater percentage of variance in single skeletal measures than they did. Clinical impressions can indeed be biased.

One linear combination of occlusal features did explain $66 \%$ of the variance in one linear combination of skeletal variables (Table IV). The skeletal pattern shown in the canonical correlation analysis was strikingly similar to a pattern described by Moyers and associates. ${ }^{42}$ In Class II subjects, they identified several distinct horizontal and vertical types. The skeletal pattern depicted in our large overjet, Class II scheme is suggestive of their horizontal type $D$ and vertical type 2. Horizontal type D has been described as a skeletal Class II with maxillary dental protraction; vertical type 2 is characterized by a flat mandibular plane, a palatal base tipped up anteriorly, and a flat anterior cranial base. They observed this combination (D-2) in 54 of 697 Class Il cases. Our data suggested that this skeletal configuration tends to have large overjet, shallow overbite, Class II molar relation, and minimal maxillary crowding, and vice versa.

This multivariate approach suggested an unusual relation (flat mandibular plane and shallow overbite) that initially appeared in conflict with previous studies. $^{4-10}$ Shallow ovcrbite alone was associated with a steep mandibular plane angle in our linear correlation analysis (Table III). However, shallow overbite plus large overjet and Class II molar relation were associated with a flat mandibular plane plus other specific skeletal features. Multivariate analysis gave insights not possible with univariate techniques.

Thus our data did lend some support to the contention that "Specific craniofacial types have typical occlusal categories associated with them." Because we were unable to discern other sets of combinations, our results did not support a generalized statement of this principle. In addition the association discovered in the 
canonical correlation analysis accounted for only two thirds of the total variance. Of more importance, all variables did not contribute equally to $R^{2}$. Three of the four occlusal variables in OCV had comparatively low weightings; therefore several (5) angular skeletal measures in SCV accounted for about one half of the overjet variation.

Singularly or in combination, features of occlusion did not depict the horizontal position of either the maxilla or mandible. This is in contrast to the conclusion of $\mathrm{McNamara}^{26}$ that "Mandibular skeletal retrusion was the most common single characteristic of . . Class II" in 8- to 10-year olds. The subjects in our sample were generally 11 to 14 years of age, at or near puberty; this is a period of marked variability in skeletal and occlusal maturation. ${ }^{1}$ Features of a malocclusion in our sample demonstrated more about horizontal and vertical maxillary-mandibular relationships, incisor position, and vertical mandibular position than they did about either horizontal maxillary or mandibular positions alone.

Finally we have shown that the relation between a malocclusion severity index and skeletal morphology was weak. No classification scheme fully represents either occlusal or skeletal variability. Orthodontic diagnosis and treatment planning should be based on characteristics and needs of the individual patient with a thorough knowledge of the variability in occlusal development and skeletal maturation.

\section{CONCLUSIONS}

We have evaluated the relation between several features of occlusion and craniofacial morphology in a sample of children in the early permanent dentition. Our results supported the following conclusions:

1. Individually and in combination, occlusal characteristics (molar relation, overjet, overbite, and crowding) were poorly associated with individual measures of craniofacial morphology.

2. A malocclusion severity index, which was based on several aspects of occlusion, did not identify craniofacial morphology.

3. Combinations of certain occlusal characteristics may be associated with specific skeletal types; however, a generalized statement of this concept could not be supported.

\section{REFERENCES}

1. Moyers RE, Wainright RL. Skeletal contributions to occlusal development. In: McNamara JA, ed. The biology of occlusal development. Ann Arbor: 1977:89-111. Center for Human Growth and Development, University of Michigan.

2. Angle EH. Malocclusion of the teeth. 7th ed. Philadelphia: SS Whitc Mfg. Co., 1907.
3. Scott J. The analysis of facial growth. AM J ORTHOD 1958; 144:507-12.

4. Hellman M. Open bite. INT J ORTHOD 1931;17:421-44.

5. Wylie WL. The relationship between ramus height, dental height, and overbite. AM J ORTHOD ORAL SURG 1946;32:51-67.

6. Schudy FF. Vertical growth versus anteroposterior growth as related to function and treatment. Angle Orthod 1964;34:75-93.

7. Hapak FN. Cephalometric appraisal of the open-bite case. Angle Orthod 1964;34:65-72.

8. Richardson AR. Skeletal factors in anterior open bite and deep over bite. AM J ORTHOD 1969;56:1 14-27.

9. Nahoum HI. Anterior open-bite: a cephalometric analysis and suggested treatment procedures. AM J ORTHOD 1975;65:51321.

10. Trouten JC, Enlow DH, Rabine M, Phelps AE, Swedlow D. Morphologic factors in open bite and deep bite. Angle Orthod 1983;53:192-211.

11. Norderval K, Wisth PJ, Boe OE. Mandibular anterior crowding in relation to tooth size and craniofacial morphology. Scand J Dent Res 1975;83:267-74.

12. Sakuda M, Kuroda $Y$, Wada $K$, Matsumoto $M$. Changes in crowding of teeth during adolescence and their relation to the growth of the facial skeleton. Trans Eur Orthod Soc 1976:93104.

13. Leighton BC, Hunter WS. Relationship between lower arch spacing/crowding and facial height and depth. AM J ORTHOD 1982;82:418-25.

14. Craig CA. The skeletal patterns characteristic of Class I and Class II, Division 1 malocclusions in norma lateralis. Angle Orthod 1951;21:44-56.

15. Blair ES. A cephalometric roentgenographic appraisal of the skeletal morphology of Class I; Class II, Division 1; and Class II, Division 2 (Angle) malocclusions. Angle Orthod 1954; 24:106-19.

16. Milacic M, Markovic M. A comparative occlusal and cephalometric study of dental and skeletal A-P relationships. AM J ORTHOD 1983;10:53-4.

17. Baldridge JP. Further studies of the relation of the maxillary first permanent molars to the face in Class I and Class II malocclusions. Angle Orthod 1950;20;3-10.

18. Drelich RC. A cephalometric study of untreated Class II, Division 1 malocclusion. Angle Orthod 1948;18:70-75.

19. Gilmore WA. Morphology of the adult mandible in Class II, Division 1 malocclusion and in excellent occlusion. Angle Orthod 1950;20:137-46.

20. Harris JE, Kowalski CJ, Walker GF. Discrimination between normal and Class II individuals using Steiner's analysis. Angle Orthod 1972;42:212-20.

21. Henry RG. A classification of Class II, Division 1 malocclusion. Angle Orthod 1973;63:414-23.

22. Hitchcock HP. A cephalometric description of Class II, Division 1 malocclusion. AM J ORTHOD 1973;63:414-23.

23. Renfroe EW. Study of the facial patterns associated with Class I, Class II, Division 1, and Class II, Division 2 malocclusions. Angle Orthod 1948;18:12-5.

24. Riedel RA. The relation of maxillary structures to cranium in malocclusion and normal occlusion. Angle Orthod 1952;22: 142-5.

25. Rothstein TI. Facial morphology and growth from 10 to 14 years of age in children presenting Class II, Division 1 malocclusion: a comparative roentgenographic cephalometric study. AM J ORTHOD 1971;60:619-20. 
26. McNamara JA. Components of Class II malocclusion in children 8-10 years of: age. Angle Orthod 1981;50:177-202

27. Wylie WL. The assessment of anteroposterior dysplasia. Angle Orthod 1947:17:97-109.

28. Johnston LE. A comparative analysis of Class II treatments. In: Vig PS, Ribbens KA, eds. Science and clinical judgement in orthodontics. Monograph 19, Craniofacial Growth Series. Ann Arbor: 1986. Center for Human Growth and Development, University of Mishigan.

29. Solow B. The pattern of craniofacial associations. Acta Odontol Scand 1966;24(Suppl 46):1-174.

30. Grainger RML. Orthodontic treatment priority index. Public Health Service Publication No. 1000, Series 2, No. 25. Washington. D.C.: US Government Printing Office, 1967.

31. Summers $\mathrm{CJ}$. The occlusal index. A system for identifying and scoring occlusal disorders. AM J ORTHOD 1971;59:552-67.

32. Moorrees CFA, Kent RL Jr. Scientific discipline in diagnosis and treatment planning. In: Vig PS, Ribbens KA, eds. Science and clinical judgment in orthodontics. Monograph 19, Craniofacial Growth Series. Ann Arbor: 1986. Center for Human Growth and Development, University of Michigan.

33. Riolo ML, Moyers RE, McNamara JA, Hunter WS. An atlas of craniofacial growth. Monograph 2, Craniofacial Growth Series. Ann Arbor: 1974. Center for Human Growth and Development, University of Michigan.

34. Moyers RE, Elookstein FL, Guire KE. The concept of pattern in craniofacial growth. AM J ORTHOD 1979;76:136-48.

35. Moyers RE, Bookstein FL, Hunter WS. Analysis of the cranio- facial skeleton: cephalometrics. In: Moyers RE, ed. Handbook of Orthodontics. 4th ed. Chicago: Year Book Medical Publishers, 1988:247-301

36. World Health Organization. An international methodology for epidemiological studies of oral diseases. Manual No 5. Geneva: 1966.

37. Grewe JM, Hagen DV. Malocclusion indices: a comparative evaluation. AM J ORTHOD 1972;61:286-94.

38. Pedhazur EJ. Multiple regression in behavioral research. 2nd ed. New York: Holt, Rinehart, Winston, 1982.

39. Morrison DF. Multivariate statistical methods. New York: McGraw-Hill, 1976.

40. SAS Institute. SAS statistical package. Cary, North Carolina: SAS Institute, 1985.

41. Björk A, Solow B. Measurements on radiographs. J Dent Res 1962;41:672-83

42. Moyers RE, Riolo ML, Guire KE, Wainwright RL, Bookstein FL. Differential diagnosis of Class II malocclusion. AM J ORTHOD 1980;78:477-94.

Reprint requests to:

Dr. Stephen D. Keeling

Department of Orthodontics

College of Dentistry

University of Florida

Box J-444, JHMHC

Gainesville, FL 32610 